\title{
A propaganda feminista luso-brasileira: as cartas de Ana de Castro Osório a Bertha Lutz*
}

\author{
Luso-Brazilian feminist propaganda: \\ letters from Ana de Castro Osório to Bertha Lutz
}

\author{
EDUARDO DA CRUZ1 \\ ANDREIA MONTEIRO DE CASTRO2 \\ ${ }^{1}$ Universidade do Estado do Rio de Janeiro. Rio de Janeiro, RJ, Brasil. \\ ${ }^{2}$ Secretaria de Educação do Estado do Rio de Janeiro. Rio de Janeiro, RJ, Brasil.
}

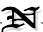

\begin{abstract}
Resumo: Edição das cartas de Ana de Castro Osório (1872-1935) a Bertha Lutz (1894-1976) existentes no Arquivo Nacional, no Rio de Janeiro, no fundo da Federação Brasileira para o Progresso Feminino. A partir da leitura dessas missivas, este artigo tece considerações sobre a ligação entre as duas líderes feministas, seus projetos, redes de sociabilidade e o papel que a escritora portuguesa ainda procura desempenhar em sua propaganda.

Palavras-chave: feminismo; relações luso-brasileiras; epistolografia; Ana de Castro Osório; Bertha Lutz.

Abstract: An edition of the letters of Ana de Castro Osório (1872-1935) to Bertha Lutz (18941976) existing in the National Archive, in Rio de Janeiro, at the fund of the Brazilian Federation for Women's Progress. From the reading of these missives, this article studies the connection between the two feminist leaders, their projects, their socialnetworks and the role that the Portuguese writer still seeks to play in her propaganda.
\end{abstract}

Keywords: feminism; Portuguese-Brazilian relations; epistolography; Ana de Castro Osório; Bertha Lutz.

Brasil e Portugal possuem fortes laços históricos e culturais, contudo as relações luso-brasileiras, principalmente nos campos da política, da cultura e das mentalidades, necessitam ainda de estudos mais aprofundados sobre determinados aspectos e períodos. Nesse ponto, Ana de Castro Osório e Bertha Lutz são dois nomes incontornáveis na história do feminismo em português. A primeira foi criadora, dirigente ou membro de uma série de associações de mulheres em Portugal. A segunda teve papel semelhante no Brasil, inclusive como fundadora e presidente da Federação Brasileira para o Progresso Feminino. Ambas estabeleceram relações com movimentos, grupos e líderes feministas de vários países. Por isso, não é de se estranhar que as duas tivessem se comunicado. $\mathrm{O}$ que este artigo pretende demonstrar é que Ana e Bertha estabeleceram uma amizade durante a estada da intelectual portuguesa no Brasil em 1922 a partir da propaganda que as unia e que permaneceram em contato trocando informações e auxiliando-se mutuamente nos dois lados do Atlântico.

É justamente o fundo da Federação Brasileira para o Progresso Feminino existente no Arquivo Nacional, no Rio de Janeiro, entre a correspondência de Bertha Lutz, que se encontram algumas mensagens de Ana de Castro Osório para a amiga brasileira. São 8 cartas e um cartão postal. As primeiras missivas foram escritas ainda no Brasil, no Rio de Janeiro e no Rio Grande do Sul, formando um conjunto com outras enviadas de Lisboa, indicando haver contato mais intenso entre o fim de 1922 e meados de 1923. E ainda uma correspondência mais espaçada entre 1927 e 1929.

Ao lidarmos com fontes primárias, que nas últimas décadas têm sido utilizadas por historiadores e pesquisadores da área de Letras na valorização de uma história cultural ${ }^{1}$, como a correspondência da escritora

\footnotetext{
* Não podemos deixar de lamentar o incêndio sofrido pelo Museu Nacional, instituição à qual Bertha Lutz esteve ligada, por sua importância histórica, cultural e de pesquisa.
} 
e periódicos, podemos reconstituir parte da rede de sociabilidade que Ana de Castro Osório estabeleceu no Brasil, suas ações e como ela articulava para divulgar seus livros e suas ideias.

Segundo a historiadora Ângela de Castro Gomes (2004), a correspondência entre intelectuais é, sobretudo, um espaço revelador de conceitos, de projetos, de posicionamentos políticos e de movimentos tanto de luta como de resistência. Uma escrita de si que, devido à natureza de seus autores, acaba por constituir e reconstituir as dinâmicas dos campos cultural, social e político do período histórico no qual se circunscrevem.

Pretendemos, portanto, com a publicação dessas cartas, contribuir com os estudos sobre as relações lusobrasileiras e com a própria história do feminismo no Brasil e em Portugal, divulgando momentos do diálogo entre duas importantes líderes feministas. Além disso, a leitura dessa epistolografia permite inferir temas que as unia, a rede de sociabilidade que articulavam através do oceano, com apoios recíprocos, e caminhos que trilhavam. Como havia uma diferença de gerações - Ana é vinte e poucos anos mais velha do que Bertha - é curioso ver a postura professoral com que a portuguesa se apresenta nas primeiras cartas, indicando rumos e partilhando projetos. Assim, enquanto a brasileira está ascendendo na luta feminista, participando de uma série de congressos internacionais, a outra começa a seguir um trajeto menos incisivo em sua propaganda, que ganha ares nacionalistas, enquanto amplia sua obra ficcional, levando-a a constantes comentários sobre sua produção e circulação.

Afinal, Ana de Castro Osório já tinha uma carreira consolidada em Portugal quando começou a buscar o público brasileiro. Resumidamente, podemos lembrar que ela foi editora, principalmente de livros infantojuvenis, literatura que ela abraçou também como autora, tradutora e pela recolha de contos tradicionais, além de ter escrito algumas narrativas curtas e romances. Também foi editora e redatora de alguns periódicos e colaborou com diversos jornais e revistas. Politicamente, Ana de Castro Osório foi defensora incansável dos direitos das mulheres e é de sua pena o texto considerado primeiro manifesto feminista português, Às mulheres portuguesas, de 1905.

Politicamente comprometida, republicana convicta, Ana defendeu, com sua pena e com ações, direitos das mulheres como a educação e a instrução, o sufrágio, o divórcio, a independência econômica, incluindo o acesso a diversas profissões e salário igual para ambos os gêneros, agindo em prol das bandeiras principais das campanhas feministas em Portugal (CASTRO, 2011; ESTEVES, 2011). Ela participou ativamente dessas lutas integrando-se em associações, como o Grupo Português de Estudos Feministas (1907), a Liga Republicana das Mulheres Portuguesas (1908) e a Associação de Propaganda Feminista (1911), entre outras.

A ligação de Ana de Castro Osório com o Brasil não é totalmente desconhecida. Além de ter vivido em São Paulo entre 1911 e 1913, acompanhando o marido Paulino de Oliveira que fora nomeado cônsul de Portugal, excursionou por várias cidades em 1922 e 1923. Inclusive, seu objetivo de alcançar o mercado brasileiro era antigo. No espólio de sua família na Biblioteca Nacional de Portugal, há a correspondência com representantes comerciais e amigos indicados a fazer divulgação de sua obra "Para as Crianças" por aqui. Os resultados nem sempre foram positivos, mas ela persistia. Ana conseguiu, contudo, que alguns de seus livros infanto-juvenis fossem aprovados para uso nas escolas e para prêmios nos estados de Minas Gerais e São Paulo². Isso demonstra um trabalho árduo de estabelecimento de relações socioculturais no Brasil, antes, durante e depois dos períodos em que esteve nesse país.

Também para as crianças, além da série em vários volumes saídos por sua própria editora e que ela busca comercializar também no Brasil (GOMES, 2016), ela publica, em 1924, Viagens aventurosas de Felício e Felizarda ao Brasil, buscando uma aproximação maior com o público e com o mercado brasileiros. No mesmo ano, lança $A$ grande aliança, com o subtítulo "a minha propaganda no Brasil", reunindo as ideias que ela propagara em uma série de conferências realizadas entre 1922 e 1923 no Rio de Janeiro, São Paulo, Curitiba, Porto Alegre, Pelotas e Santa Maria aproveitando as comemorações do centenário da independência. Em 1927, sai o romance Mundo Novo, sobre uma escritora feminista que busca nova vida aqui.

Também já começam a aparecer estudos com algumas relações de sociabilidade entre ela e outras escritoras, educadoras e feministas brasileiras percebidas pela troca de correspondência e mesmo referências publicadas (GOMES, 2013 e 2016; LOUSADA, 2015; LOUSADA e LAGUARDIA, 2013; PEREIRA, 2015). Algumas pesquisas têm se debruçado mormente sobre o livro $A$ Grande Aliança (GOMES, 2011 e 2013). Inclusive, é um ponto recorrente nesses estudos as diversas estratégias de Ana de Castro Osório para inserção de seu nome no mercado literário brasileiro e na ampliação de seus contatos, algo que também percebemos pela leitura de suas cartas a Bertha Lutz.

Parece ter sido em sua segunda viagem ao Brasil o estabelecimento de relações com a jovem Bertha. $\mathrm{O}$

\footnotetext{
Como Uma lição de História (1909), As boas crianças, nona série da coleção "Para crianças", Os nossos amigos (1910?) - em coautoria com o esposo -, Lendo e aprendendo (1913) - publicado em São Paulo, pela Empresa de Propaganda Literária Luso-Brasileira -, e $O$ livrinho encantador (1923) (REMÉDIOS, 2000).
} 
Rio de Janeiro vivia as comemorações do centenário da independência com a exposição mundial. É justamente em 1922, aproveitando essa efervescência cultural, que a feminista brasileira vai organizar um congresso reunindo representantes de vários estados e países. Os jornais da época festejavam a iniciativa, como se vê no artigo "O feminismo no Brasil", publicado n'O País:

A nossa capital hospeda já algumas senhoras de alta representação social e moral nos seus respectivos paizes, como a notável escriptora D. Anna de Castro Osorio, e como a socióloga norte-americana miss Elisabeth Babcock, e outras vindas expressamente ao Brasil para discutir e aventar idéas no Congresso Feminista, a realizar-se, agora, no Rio, por iniciativa da Federação Brasileira das Ligas pelo Progresso Feminino (O Paiz, n. 13.932, 12/12/1922, p. 3).

Bertha, desde suas primeiras ações como feminista, evidenciava a sua ambição de se integrar às mais expressivas redes internacionais, colocando o Brasil, de fato, nos rumos do movimento pelo sufrágio feminino e pela inserção da mulher no mercado de trabalho. Logo após a sua volta da Europa e sob a publicidade de seu grande êxito no concurso para um cargo no Museu Nacional, a bióloga recém-formada, mas já muito bem relacionada, representava o Brasil no Conselho Feminino Internacional na Conferência Geral da Organização Internacional do Trabalho (OIT), na qual foram aprovados os princípios da igualdade salarial para ambos os sexos e a inclusão da mulher no serviço de proteção aos trabalhadores (SOIHET, 2006).

Mas, para fazer com que o feminismo realmente se propagasse em solo pátrio, era preciso também que as suas ideias fossem divulgadas por grupos nacionais. Visando alcançar este objetivo, em 1920, Bertha, juntamente com Maria Lacerda de Moura, fundava a Liga para a Emancipação Intelectual da Mulher (LEIM). A associação propiciava a reunião, sobretudo, de senhoras das classes mais abastadas e com alta escolaridade que se valiam de sua posição financeira e de seu prestígio social para a defesa da emancipação social, política, econômica e intelectual das mulheres (SOIHET, 2006).

Embora tenha feito muito sucesso, devido a diferenças ideológicas de suas fundadoras, a Liga acabou por não ser muito longeva. Segundo Miriam L. Moreira Leite (2005), logo ficaram patentes as reservas da moderada líder do Rio de Janeiro diante do radicalismo da escritora mineira ligada à causa anarquista.

Praticamente desligada de sua antiga parceira, em 1922, Bertha Lutz viaja aos Estados Unidos como representante brasileira na I Conferência Pan-Americana de Mulheres, realizada em Baltimore, firmando contatos com organizações sufragistas internacionais.
Completamente inserida neste contexto e travando contatos com líderes de diversas nações, ao retornar ao Brasil, Bertha dissolve a LEIM e funda a Federação Brasileira para o Progresso Feminino (FBPF).

Para organizar o grande primeiro evento da Federação, conforme a primeira carta analisada nos leva a crer, Bertha se valeu da experiência e da rede de relacionamnetos da escritora portuguesa, Ana de Castro Osório. As duas estavam preparando em conjunto a programação da Conferência Pelo Progresso Feminino no Rio de janeiro, que contou também com a participação das estadunidenses Charrie Chapman Catt, presidente da Liga Pan-Americana da Mulher, e Anita Van Lennep, e da líder feminista holandesa, Rosette Susana Manus. Ana indicava uma sequência de conferências que seriam proferidas por ela antes que Bertha fizesse "a de luxo", que deveria ser sobre "A mulher em Portugal e no Brasil". As palavras da escritora "em que o feminismo entra como corolário lógico" (28/10/1922), como ela se refere, foram proferidas em Porto Alegre ${ }^{3}$, além da primeira, a que Bertha teria assistido 4 .

Contudo, Ana acabou por não participar do congresso como anunciado nos jornais por ter já iniciado sua viagem ao Sul. É o que ela informa na carta de 11 de dezembro de 1922, que deve ter acompanhado um texto de sua autoria sobre o feminismo em Portugal, provavelmente para colaborar com o que ela esperava ser a conferência de Bertha Lutz.

A presença de Ana de Castro Osório no congresso com líderes feministas de vários pontos do país e representantes estrangeiras teria sido a sua última grande participação no movimento feminista, se ela tivesse ficado no Rio de Janeiro. Segundo João Esteves, “o desencadear da Grande Guerra fez emergir a sua última fase feminista, a de feminista nacionalista" $(2014$, p. 57) e, ao longo da década de 1920, Ana empenha-se na Cruzada das Mulheres Portuguesas e descompatibiliza-se com o regime republicano parlamentarista, recusa ser condecorada, e segue o caminho dos filhos, envolvidos com o movimento nacionalista. "Era o fecho de um ciclo, por vontade própria, da líder feminista" (ESTEVES, 2014, p. 59).

Inclusive, a ligação dos filhos com o movimento nacionalista em Portugal foi um dos tópicos da entrevista que Osório concedeu ao Jornal do Brasil, publicada em 31 de março de 1923, na qual mostra ser efetivamente sua maior inspiração naquele momento:

\footnotetext{
3 No Conservatório de Música, dia 1 de janeiro de 1923 (Jornal do Commercio, a. 97, n. 1, 01 e 02/01/1923, p. 2).

4 Provavelmente a conferência sobre as pequenas indústrias regionais portuguesas, proferida na Câmara Portuguesa de Comércio, no Rio de Janeiro, no dia 21/10/1922 (O Paiz, n. 13.881, 22/10/1922, p.4) e comentada em outras cartas.
} 
Meu filho tem um unico ideal, como eu, como todos os que somos e sabemos ser portuguezes: - engrandecer a Patria, collocar Portugal onde deve estar, onde é logico que esteja, onde a Historia o manda estar, num dos primeiros logares da civilisação moderna. Pelo seu ideal foi preso e esteve 6 mezes á mercê das reviravoltas politicas, acompanhado pelo irmão e pelos moços valentes e heroicos, que crêem no futuro dum maior Portugal, alliado do Brasil economica, moral e politicamente, para a grande expansão da raça e da lingua commum (Jornal do Brasil, n. 77, 31/03/ 1923, p. 5).

Suas ações e palavras passam a carregar o feminismo apenas "como corolário lógico", pois a questão nacional se sobrepõe à luta das mulheres. No entanto, Ana parece não abrir mão da propaganda e incentiva Bertha Lutz a que siga utilizando a imprensa periódica para esse fim, ao mesmo tempo em que procura divulgar o nome e os trabalhos da amiga brasileira no Rio Grande do Sul. Tanto que, além de proferir sua conferência "O idealismo da nossa Raça sempre heroica e sempre moça" no Centro Português Dr. Afonso Costa em 19 de novembro (O Paiz, n. $13.909,19 / 11 / 1922$, p. 5), repete-a para um grupo maçom na cidade do Rio Grande, junto ao qual defende a entrada de mulheres na maçonaria brasileira, tal como em Portugal, indicando o nome de Bertha Lutz para organizar esse núcleo, e liga a presidente da FBPF a uma diretora de escola em Santa Maria, Margarida Lopes, que "dispõe da imprensa para a propaganda" (06/01/1923).

Assim, mesmo que distante do Rio de Janeiro, Ana C. Osório acompanhava as discussões do congresso e, aproveitando sua estada por lá, procurava ampliar as redes de sociabilidade de Bertha Lutz no Rio Grande do Sul. $\mathrm{Na}$ verdade, essas cartas revelam que, mesmo afastada do movimento político feminista, Ana continuava defendendo sua propaganda e "as ideias emancipadoras pelo trabalho" (06/01/1923) mais do que a luta política propriamente dita. Esse tema tinha relação direta com o que estava sendo debatido na Conferência pelo Progresso Feminino, "como a collaboração da mulher, nos campos, nas officinas, nos hospitaes, no magistério, no lar e na sociedade, deva ser prestado ao homem, de modo que este reconheça o valor real, que é alto e brilhante, do seu contingente" (Jornal do Brasil, n. 303, 20/12/1922, p.9) e que contava inclusive com representantes da União dos Empregados do Comércio do Rio de Janeiro, Carmen Cunha e Nair Braga, que defenderam suas ideias sobre o "papel da mulher no commercio, na industria e no funcionalismo" (Jornal do Brasil, n. 305, 22/12/1922, p. 7). Afinal, o acesso das mulheres ao mercado de trabalho e as condições em que isso se dava, sua aceitação, respeitabilidade, remuneração, etc. eram pontos importantes das lutas feministas. Podemos lembrar, inclusive, o texto de Virginia Wolf, no qual ela compara sua atividade como escritora com a das proletárias e percebe que:

Os obstáculos ainda são imensamente grandes - e muitos difíceis de definir. De fora, existe coisa mais simples do que escrever livros? De fora, quais os obstáculos para uma mulher, e não para um homem? Por dentro, penso eu, a questão é muito diferente; ela ainda tem muitos fantasmas a combater, muitos preconceitos a vencer. Na verdade, penso eu, ainda vai levar muito tempo até que uma mulher possa se sentar e escrever um livro sem encontrar com um fantasma que precise matar, uma rocha que precise enfrentar. $\mathrm{E}$ se é assim na literatura, a profissão mais livre de todas paras as mulheres, quem dirá nas novas profissões que agora vocês estão exercendo pela primeira vez? (WOLF, 2012, p. 17).

Contudo, na questão da ligação entre o feminismo português o brasileiro, Bertha não seguiu a proposta de Ana de Castro Osório e, a partir da ideia de centenário da independência, comentou o papel da mulher brasileira na sua fala de abertura. Também, um dos temas mais debatidos na conferência não foi uma união luso-brasileira feminista, mas "a mulher nas relações pan-americanas" (Jornal do Brasil n.306, 23/12/1922, p.9), seguindo um caminho diverso do luso-brasilianismo defendido nas conferências de $A$ grande aliança.

Mesmo assim, a ligação entre as duas feministas não esmorece e a coloquialidade da escrita de Ana de Castro Osório, com frases bem próximas do discurso oral, mostra a proximidade do tratamento. Por isso, quando Bertha vai à Europa em 1923 e não passa por Lisboa, sofre reprimendas da amiga. por essa falta. $\mathrm{Na}$ volta, apesar de Ana ter ficado à espera sem conseguirem se encontrar, fez chegar às mãos de Lutz os textos solicitados sobre as indústrias regionais portuguesas e o trabalho feminino.

Chama a atenção nessas missivas a dedicação que a autora de literatura infantil passa a dar à escrita de romances e ao mercado livresco no Brasil. São várias referências à sua produção literária: "Quando puder venha aqui um bocado para lhe mostrar alguns capítulos dum romance que estou a acabar e as conferências." (28/10/1922); "Desde que vim já acabei o meu romance que lhe há de agradar pelas questões femininas que agita." (26/06/1923); "Já estou fazendo outro [romance] com ligação com o Brasil... Aguardo com muito interesse as suas notícias." (01/10/1927).

Como se vê, Ana se dedica a uma nova campanha pelo feminismo, formando mentalidades através da literatura. Porém, nesse quesito, ela não parece tão confiante. Notase que o tom de mestra instruindo discípula nos caminhos da propaganda feminista presente na organização dos temas e das sequências das conferências se desfaz e a 
romancista quer saber as opiniões da leitora Bertha. Afinal, Ana de Castro Osório buscou sempre público para suas publicações. Não descuidaria desse aspecto em sua nova fase de escritora.

Ana passa então a incluir o filho na campanha pela divulgação de seus produtos. Na carta de 26 de junho de 1923, há o aviso de que o jovem seguiria para o Brasil no vapor Caxias e pede ajuda de Bertha Lutz para que o livro Lendo e aprendendo fosse também aprovado para uso nas escolas do Rio de Janeiro. A carta de julho do mesmo ano indica que o José veio ao Rio para continuar a propaganda da mãe, sobretudo na divulgação dos livros de sua editora. Ana pede a Bertha que o ajude nessa tarefa: "Seria muito bom que o apresentasse e recomendasse de modo a serem aprovados os livros no Rio e a que o professorado gostasse de os adotar." ${ }^{5}$ E em 1927, a escritora portuguesa envia seu romance à amiga brasileira e solicita novamente ajuda na propaganda junto à imprensa. Tanto que, em 1928, confirma que encaminhou seu livro para os jornais por intermédio da Câmara Portuguesa de Comércio. Ela chega a pedir que a própria Bertha faça divulgação de sua obra na página sobre feminismo que passa a dividir com Orminda Bastos n'O País.

Enquanto isso, em Portugal, Ana de Castro Osório procura difundir as ações de Bertha Lutz em prol do feminismo. O Século, de Lisboa, publica um artigo sobre as lutas feministas brasileiras e destaca o papel de Bertha. As cartas demonstram a rede de sociabilidade articulada por Ana para isso: trata-se de um texto de Virgínia Quaresma, na seção sob responsabilidade de Maria da Conceição Pereira de Eça, com a reprodução de um retrato de Bertha Lutz a partir de um recorte de jornal enviado do Brasil por Joaquina Machado Dantas de Carvalho, filha de Bernardino Machado.

O artigo comemora a possibilidade da concessão do voto às brasileiras. Por isso, Quaresma, assinando simplesmente "VI", destaca a atuação de Lutz nessa campanha, recordando, inclusive, o congresso de 1922: "Nunca mais esquecerei essa importante assembléa de vultos da 'élite' feminina do Brasil, que vinham desde os Estados do Norte ao Rio Grande do Sul, avolumar o

\footnotetext{
5 Bertha acabou por não encontrar José Osório de Oliveira nessa viagem, como indica a carta datilografa a Ana de Castro Osório, de 24/11/1923, existente no mesmo acervo: "Quando o Sr. seu filho cá esteve antes de partir para São Paulo, não foi-me infelizmente, dado um serviço de urgência, que me foi empurrado, possível ter o prazer de conhecêlo pessoalmente. // Por ocasião de seu regresso, só soube que aqui se achava, quando já se dispunha a partir, havendo desencontro e atraso em me ser comunicado estar ele aqui. // Sinto deveras e peço que me perdoe a aparente falta de gentileza, que the asseguro foi profundamente involuntária, pois muito desejava o conhecer" (Q0.ADM.COR. A1923.4.p10). No entanto, os dois acabaram por se relacionar também, como indica o cartão postal remetido por José a Bertha em 29/12/1930: "Que o novo ano traga todas as venturas, a si e ao Brasil, é o que deseja o seu ingrato mas dedicado (passe a contradição) amigo respeitoso e admirador: José Osório de Oliveira" (Q0.BLZ.COR.CAP.19).
}

audacioso apostolado iniciado por Berta Lutz" (O Século, 11/02/1928, p. 5) ${ }^{6}$. E termina ainda com uma memória pessoal de sua ligação com a brasileira:

\begin{abstract}
No final da sessão, que marcou gloriosamente a primeira "étape" do feminismo brasileiro, Berta Lutz, olhar sereno e resoluto, diz-me na sua voz ondulante de convicção e ternura:

- Creia. O Brasil está conquistado pelas mulheres. Nós seremos, amanhã, valores políticos, como o são os homens. Daqui a cinco anos, a mulher brasileira terá o direito ao voto. (O Século, 11/02/1928, p.5).
\end{abstract}

Seguindo essa mesma estratégia, Ana de Castro Osório procura ligar sua rede de sociabilidade à de Bertha Lutz. Indica, em 1928, que a brasileira procure em Santa Teresa a filha de Bernardino Machado. No ano seguinte, sugere que Bertha, a caminho da Alemanha para o II Congresso da Aliança Internacional pelo Sufrágio Feminino, procure sua amiga Silvia Emil Wiesener em Hamburgo. E ainda solicita que apresente um primo de Maria Pereira de Eça às suas relações no Brasil. Além disso, comenta e pergunta a opinião de Lutz sobre outras escritoras e feministas relacionadas com os congressos dos quais a brasileira participa.

Quanto ao movimento feminista propriamente dito, parece haver realmente um distanciamento nas ações públicas. Tal como João Esteves já apontou, Ana de Castro Osório passa a se dedicar à Cruzada das Mulheres Portuguesas, com um cunho nacionalista e de intensa atividade em várias áreas 7 . No entanto, é preciso destacar o modo como a feminista nacionalista portuguesa valoriza essa sua ação nesse momento, sem ignorar que "valorizar a importância social e económica das mulheres em tempos de crise, também contribuiu para atenuar o papel das organizações feministas como grupo de pressão" (ESTEVES, 2011, p. 44).

No fundo, há uma mudança na campanha de Ana de Castro Osório. Ela apresenta a situação portuguesa a partir de suas próprias ações: "Aqui trabalha-se pouco pela conquista dos direitos, mas a necessidade obriga a mulher a trabalhar e isso transforma a sociedade sem darem por isso." (01/10/1927). E demonstra que a condição piorou a partir da ditadura. A carta de 1929 indica que Portugal não enviaria ninguém ao congresso de Berlim por não terem reatado ainda os laços com a Alemanha - lembrando que

\footnotetext{
6 Agradecemos a Lívia Coutinho a digitalização e o envio do artigo.

7 "A obra da Cruzada foi diversificada e mesmo notável aos mais diversos títulos e a imagem que dela foi legada às gerações futuras faz jus ao transcender a barreira da caritativa simples para um enquadramento mais complexo, em que o próprio nome "Cruzada" simultaneamente se cola e dissocia da peregrinação e acompanhamento que a história consignara para esta expressão. Assim, parece-nos de realçar uma clara tentativa de apropriação do termo "Cruzada", desta feita, a reconfigurar, aquilatando-a ainda que acompanhando a beligerância revestindo-a do carácter secular e laico" (LOUSADA, 2011, p. 671-672).
} 
os dois países estiveram em lados opostos na Primeira Guerra. Além disso, há um tom de lamento quanto à situação das mulheres portuguesas durante a ditadura nacional, que parece pôr em questão o movimento que ela e os filhos apoiavam em 1922:

Aqui o problema do sufrágio feminino interessa pouco, mormente agora que não há parlamento nem câmaras municipais, nem juntas, nem nada. Vivemos num regímen esquisito de ordem do dia. Nem se sabe o que foi ontem, o que é hoje, nem o que será amanhã. As mulheres andam preocupadas com a fome, com a alta da vida, com o corte em pensões... Enfim, numa trapalhada! (13/06/1929).

Portanto, como lutar pelo sufrágio quando não havia mais eleições? Além disso, outras questões se tornaram prementes, como a própria sobrevivência posta em risco com a falta de dinheiro e a alta do custo de vida. O nacionalismo defendido anteriormente a traíra, tal como a república portuguesa traiu as causas feministas.

Por outro lado, Ana de Castro Osório queria ainda saber das novidades no movimento internacional, quem ia aos congressos feministas, como estava a propaganda no Brasil e o que se discutia nos jornais. Essas são demandas que se repetiam em suas cartas à Bertha Lutz na segunda metade da década de 1920. "Conte muita coisa e diga algumas notícias interessantes para os jornais de cá. Sempre se vai deitando o barro à parede." (13/06/1929) é um de seus últimos pedidos. Isso mostra que, por mais que suas ações e mesmo sua ideologia política tenham se alterado, Ana não deixava de valorizar o papel da imprensa periódica como instrumento de propaganda feminista e que continuava a perceber que os avanços e as conquistas das mulheres em outros países poderiam contribuir para as lutas locais.

Assim, ao lermos essas cartas, percebemos primeiramente o caráter internacionalista do feminismo das primeiras décadas do século XX, apesar do caráter nacionalista das últimas ações de Ana de Castro Osório. Nota-se, inclusive, que as duas mulheres de ação tinham diversos interesses em comum, sobretudo no que tange ao acesso ao mercado de trabalho e às suas condições. Além disso, há apoios mútuos. Ana solicita a ajuda de Bertha Lutz para a divulgação de sua obra e para ampliar as relações de seus protegidos. Em contrapartida, ela consegue em Portugal a divulgação das ações feministas capitaneadas por Bertha. As missivas de Ana de Castro Osório a Bertha Lutz confirmam o desejo da primeira de uma aliança lusobrasileira feminista através de propaganda, valorização dos empreendimentos femininos e da literatura, ao mesmo tempo em que apresentam a Bertha suas próprias ideias e atuações em prol do feminismo.

\section{Carta $1^{8}$}

Rio 28-10-19229,10

Minha querida amiga

Então o que é feito de si e do júri que nunca mais deu sinal de vida?!

Tive muita pena de não ir à Noruega ${ }^{11}$ por sua causa e pelo resto, mas além da chegada das minhas amigas, como chovia muito tive receio de não poder chegar lá com a dor reumática violenta que estes dias me fazem num joelho. Hoje estou eu assim pois se não estivesse em lugar de escrever procuraria vê-la pois já tenho saudades das nossas conversas em que tantas impressões de conjunto temos.

Salve a nossa propaganda! Lembra-se que the disse que oferecera duas conferências à "Agricultura" e que aceitaram amavelmente, o dr. Calmon ${ }^{12}$ e o diretor do ministério?

Pois aceitaram, mas ficou por isso mesmo... Ora é conveniente que faça mais 2 conferências antes da nossa. Tenho estado a pensar e parece-me isto mais conveniente assim. $1^{\circ}$ as conferências sobre - os perigos do urbanismo - a seguir a continuação "O regresso à terra".

Isto são coisas de ordem geral e em que o feminismo entra como corolário lógico, como na que ouviu. O público será escolhido e ponderado, não ficam assustados... depois anuncia-se a tal que é sua: "A mulher em Portugal e no Brasil" e dessa a minha amiga fará o que entender, devendo ser a de luxo. Parece-me que isto assim seria mais conveniente para os nossos fins. Quando puder venha aqui um bocado para lhe mostrar alguns capítulos dum romance que estou a acabar e as conferências.

Creia-me com a maior simpatia sua muito dedicada amiga.

Ana C. Osório

P. S. afinal o Congresso Jurídico ${ }^{13}$ resultou bem, não? Já conheço a M. ${ }^{\text {e }}$ Chrysanthème ${ }^{14}$... conhece?

\footnotetext{
Critérios de edição: Optamos por uniformizar a apresentação, com data alinhada à esquerda; assinatura e despedida o mais próximo possível da disposição original; em itálico o que estava sublinhado no original e os títulos de livros e periódicos; mantivemos a pontuação original incluindo vírgulas para facilitar a leitura (esses poucos casos estão entre [1); desdobramos as palavras abreviadas; atualizamos a ortografia para a norma padrão vigente no Brasil.

9 BR RJANRIO Q0.ADM.COR.A1922.7.p1-4

${ }^{10}$ Carta manuscrita, em papel timbrado do Hotel Avenida.

${ }^{11}$ Pavilhão da Noruega na exposição internacional do centenário da independência, inaugurado em outubro.

12 Talvez esteja se referindo a Miguel Calmon Du Pin e Almeida (18791935), eleito deputado federal em 1921 e, pouco depois, ministro da Agricultura, Indústria e Comércio do governo de Artur Bernardes a partir de novembro de 1922. (https://ihgb.org.br/perfil/userprofile/ MCduPAlmeida.html).

${ }^{13}$ O Congresso Jurídico Nacional aconteceu em outubro de 1922.

${ }^{14}$ Pseudônimo da poeta, contista, cronista e escritora de literatura infantil Cecília Bandeira de Melo Rebelo de Vasconcelos (1870-1948), filha de Emília Bandeira de Melo (conhecida pelo pseudônimo Carmen Dolores) (COELHO, 2002, p. 125).
} 


\section{CARTA 2}

Cidade do Rio Grande ${ }^{15}$

$11-12-1922$

Querida Amiga

Não sei se poderei assistir ao seu congresso, mas pode dizer que estou trabalhando pela sua causa.

Espero dar-lhe em breve boas notícias.

No correio seguinte segue a minha memória: $\mathrm{O}$ feminismo em Portugal - ou melhor "O problema feminista em Portugal'.

Fiz aqui uma pequena fala numa importante reunião da maçonaria ${ }^{16}$ advogando a entrada das mulheres nas condições de igualdade que temos em Portugal. Lembrei o seu nome como a mais capaz de fazer o pequeno núcleo que é preciso para orientar lá dentro e cá fora.

Saudades a D. Valentina ${ }^{17}$.

Um afetuoso abraço da sua amiga certa

Ana C. Osório

\section{CARTA 3}

$$
\begin{array}{r}
\text { R. G. do Sul }{ }^{18,19} \\
\text { Santa Maria } \\
6-1-1923
\end{array}
$$

Querida Amiga Bertha Lutz - Muito vagamente têm chegado aqui os ecos do seu Congresso. Em todo o caso tive o prazer de a ver na Revista da Semana.

Apesar de não ter assistido[,] olhe que não deixei nunca de estar convosco! Tenho feito bastante propaganda, e aconselho-a a não abandonar este meio para a sua propaganda pois é um onde as ideias emancipadoras pelo trabalho encontrarão campo mais fácil. Aqui há o luxo de serem estancieiras, as senhoras mais finas, já é um bom ponto de partida para o trabalho agrícola... Depois aí lhe darei as minhas notas de observação direta.

Agora só lhe quero dizer que encontrei aqui um belo elemento que ponho em comunicação consigo. Chama-se D. Margarida Lopes, é diretora duma esplêndida escola primária superior (embora lhe chamem elementar) e tem aqui no Estado muito prestígio.

É muito simpática; está perfeitamente de acordo com o seu programa e dispõe da imprensa para a propaganda.

Um grande abraço à D. Valentina.

Para si a expressão da minha muita simpatia e afeto.

Ana C. Osório

15 BR RJANRIO Q0.ADM.COR.A1922.7.p.5

${ }^{16}$ No mesmo arquivo consta uma carta-convite à conferência de Ana de Castro Osório (BR RJANRIO Q0.ADM.COR.1922.p1) sobre o tema "O idealismo da nossa Raça sempre heroica e sempre moça" no Polytheama Rio-Grandense com um carimbo da loja maçônica Filantropia do Rio Grande.

${ }^{17}$ Provavelmente, Valentina Biosca, que "durante o I Congresso Internacional Feminista, realizado no Rio de Janeiro em dezembro de 1922, apresentou uma tese sobre o Trabalho Feminino nas Fábricas" (SCHUMAHER; BRAZIL, 2000, p. 518).

${ }^{18}$ BR RJANRIO Q0.ADM.COR.A1923.4.p1-3

${ }^{19}$ Carta manuscrita, em papel timbrado da associação "Pela Pátria".

\section{CARTA 4}

26-6-1923 Lisboa $^{20,21}$

Minha querida amiga

Fiquei muito triste por receber carta sua de Paris, tendo passado por Lisboa sem bater no ferrolho, como se costuma dizer e não dando esperanças nenhuma de voltar por aqui.

Com respeito ao seu pedido sobre indústrias regionais, eu de pronto não lhe posso enviar um estudo completo porque tenho ainda por organizar as minhas obras sobre o assunto, mas a minha amiga pode pedir na Câmara do Comércio a minha conferência. Eu ofereci uma a D. Valentina.

Se a minha amiga quisesse talvez lhe pudesse arranjar uma rendeira de Peniche e outras de Vila do Conde que fosse ensinar no Rio em comissão e levaria os modelos. A muitas amigas é que devia vir por cá estudar o assunto. As indústrias regionais estão hoje muito interessantes em Portugal pois a desvalorização da moeda permite a sua procura e venda por preços elevados.

Então gostou da representante do Conselho Nacional ao Congresso de Roma ${ }^{22}$ ? É uma boa senhora.

O meu filho vai no Caxias ${ }^{23}$ no dia 26 de Julho. Por ele lhe enviarei mais notícias.

Não se esqueça de recomendar os meus livros para as escolas do Rio pois a sua orientação, especialmente do Lendo e aprendendo serve-lhe muito bem para a sua propaganda do trabalho feminino e pequenas indústrias.

Aceite um grande e afetuoso abraço da sua muito amiga.

Ana C. Osório

Desde que vim já acabei o meu romance que lhe há de agradar pelas questões femininas que agita. Estou também já a publicar as minhas conferências aí realizadas.

Mais um abraço.

Ana

\section{CARTA 5}

Lisboa 3-7-192324,25

Minha grande amiga

Tive muita pena de não a ver e fiquei toda a manhã à sua espera e depois da visita do seu emissário

20 BR RJANRIO Q0.ADM.COR.A1923.4.p4-5

${ }^{21}$ Carta manuscrita, em papel timbrado com ilustração de um lobo sobre a expressão "homo homini lúpus". Apresenta pequenos rasgos no vinco da dobra.

22 A representante do Conselho Nacional das Mulheres Portuguesas e do governo português ao Congresso Internacional Feminista de Roma foi Adelaide Cabete (1867-1935) (cf. LOUSADA, 2017, p. 89). "Adelaide Cabete foi médica, higienista, publicista, socióloga, maçona, republicana, socialista, livre-pensadora, educadora e feminista" (LOUSADA, 2010, p.25).

23 José Osório de Castro e Oliveira chegou ao porto do Rio de Janeiro, com 22 anos, no dia 4 de agosto de 1923. (BR RJANRIO OLO.RPV.PRJ.18825).

24 BR RJANRIO Q0.ADM.COR.A1923.4.p6-9

${ }^{25}$ Carta manuscrita, em papel timbrado com ilustração de um lobo cercado pela expressão "homo homini lúpus". 
esperei de tarde. Eu não pude ir a bordo por estar muito tolhida do reumatismo e por ter uma pessoa a vir aqui das 2 às 4 por graves questões de negócios. A carta que lhe mandei estava escrita para ir para o Rio, julgando-a já ali, mas como recebi a sua $2^{\underline{a}}$ carta sempre arranjei as cópias que tinha sobre o assunto. Devo ter mais coisas, mas tenho a minha vida ainda muito embaralhada. Agora vou pôr em ordem as minhas papeladas e publicar um livro sobre pequenas indústrias regionais artísticas. Depois irá tudo.

Esta vai-lhe ser levada pelo meu filho José que vai para aí continuar a minha propaganda. Peço-lhe o auxilie com a boa vontade que sempre lhe encontrei. Seria muito bom que o apresentasse e recomendasse de modo a serem aprovados os livros no Rio e a que o professorado gostasse de os adotar.

Diga-me se gostou do que lhe mandei em publicações e cópias.

Um abraço da sua muito dedicada amiga,

Ana C. Osório

A Virgínia Quaresma ${ }^{26}$ vai brevemente para aí. Ela tencionava ir esperá-la, mas não soube a horas.

\section{CARTA 6}

$1-10-1927^{27}$

Queria Amiga

Nunca mais tive notícias suas nem dos seus trabalhos pela nossa causa! Como vi hoje um telegrama dizendo que a minha amiga continua na brech $a_{2}$ sei que está aí e nas mesmas disposições de espírito... Aí vai pois mais uma acha para a sua fogueira... Espero que agrade o que digo das feministas de que a minha amiga é a incontestável chefe... Escreva-me.

E a sua secretaria? Aqui trabalha-se pouco pela conquista dos direitos, mas a necessidade obriga a mulher a trabalhar e isso transforma a sociedade sem darem por isso.

Veja se é possível fazer aí propaganda deste romance, porque sendo assim posso oferecer aos jornais, em caso contrário (para o recebemos e agradecemos) não vale a pena porque as edições são pequenas e caras e aqui vende-se bem. Eu acabo de mandar um ao presidente da sua República. Era bom saber-se se o recebeu.

Já estou fazendo outro com ligação com o Brasil... Aguardo com muito interesse as suas notícias. de ideias

Um grande abraço da muito amiga e camarada

Ana C. Osório

\footnotetext{
${ }^{26}$ Foi a primeira jornalista portuguesa a exercer a profissão como a conhecemos atualmente, "fazendo reportagens, entrevistas, crônicas". Nasceu em 1882 e faleceu em 1973 (CASTRO \& ESTEVES, 2005: 889). ${ }^{27}$ BR RJANRIO Q0.ADM.COR.A1927.15.p1-2.
}

\section{CARTA 7}

$6-3-1928^{28,29}$

Querida Amiga

Recebi hoje a sua carta que muito estimei. Deve ter recebido aí o Século de 11 de Fevereiro em cuja página feminina dirigida pela minha amiga Maria de Eça vem o retrato que eu arranjei dum recorte que daí me mandou a minha amiga Joaquina Machado Dantas de Carvalho, filha do sr. Bernardino Machado, uma grande feminista, que gostaria que procurasse $-\mathrm{R}$. Petrópolis 152 - Vista Alegre - caminho do Silvestre ${ }^{30}$.

Sobre a propaganda do livro, enviei para os jornais por intermédio da Câmara de Comércio Portuguesa. Vamos a ver o que eles dizem. Nós não lemos aqui os jornais daí. Mas dê-me a folha do País ${ }^{31}$ que trata da nossa questão, que em troca mandar-lheei a do Século. O artigo a seu respeito é da Virgínia Quaresma.

Na sua página é que pode referir-se ao livro e dar a sua opinião às mulheres. As mulheres aqui fazem pouco, mas a ideia agora vai por si própria.

Em que relações estás com a Revista Feminina de S. Paulo?

Saudades.

amiga Ana de Castro Osório

\section{CARTA 8}

Lisboa $13-6-1929^{32}$

Querida amiga

Fiquei muito contente com o seu rádio e muito descontente com o seguimento.

Toda a tarde telefonamos para a C. ${ }^{\mathrm{a}} \mathrm{e}$ de lá diziam que o "Cap Polonio" entraria e embora não atracasse[,] os passageiros podiam desembarcar.

Como não apareceu[,] às 8 da manhã telefonamos - já tinha chegado e partido de madrugada sem ter saído ninguém. Que aborrecimento! E tanto que tínhamos que conversar!

Eu não vou a Berlim ${ }^{33}$ e não sei se daqui foi alguém. Naturalmente não. Nós agora estamos muito afastados da Alemanha. Ainda verdadeiramente não tornamos a ligar. Eu tenho em Hamburgo uma grande amiga, que é alemã do Brasil. Se passar por lá[,] procure-a e dê-lhe um abraço. É Silvia Emil Wiesener - Isestr. 89 - Hamburgo 37 - Sabe que me interessa agora mais do que tudo a literatura? Fazer romances com as nossas ideias a ver se assim compreendem

\footnotetext{
${ }^{28}$ BR RJANRIO Q0.ADM.COR.A1928.14.p1-2

${ }^{29}$ Cartão postal Lusitania Editora, Limitada - Coleção "Para as Crianças", com selos ( 2 de 40c. e 2 de 10c.), carimbo Lisboa Central e carimbo Estácio de Sá - Rio), destinado a "Bertha Lutz - Federação Brasileira pelo Progresso Feminino / Matoso 161 / Rio de Janeiro / Brasil".

${ }^{30}$ Bairro de Santa Teresa, Rio de Janeiro.

31 A partir da edição n. 15868, de 31/03/1928, O País passa a ter uma seção "Feminismo", de responsabilidade de Bertha Lutz e Orminda Bastos.

32 BR RJANRIO Q0.ADM.COR.A1929.20.p1-8

${ }^{33}$ Realizou-se, em Berlim, em 1929, o II Congresso da Aliança Internacional pelo Sufrágio Feminino, no qual Bertha Lutz foi a representante brasileira.
} 
melhor. - Pelo telefone falei com a Bensaúde que conheceu em Paris e é sua amiga. Lembra-se dela?

Venha com mais tempo para podermos conversar. Queria saber muita coisa do movimento no Brasil do qual só me chegam os ecos... Por que não combina vir num vapor da C. ${ }^{a}$ e esperar aqui outro seguinte, ou então venha pelo comboio. Previna-me com tempo e não deixe de vir porque teremos muito que dizer. Está agora a realizar-se aqui um Congresso dos Antigos Combatentes da Guerra em que a "Cruzada das Mulheres Portuguesas", de que sou a Presidente, faz parte. Fiz para ele um relatório de que lhe darei depois uma cópia.

É interessante para mostrar o que é o trabalho administrativo da mulher. De tudo quanto existiu como agremiações da guerra, a nossa foi a maior que se manteve e tem casa e dinheiro de modo a salvar a "Liga dos Combatentes" que não tinha casa, a "União Colonial" (de homens) que não tinham também casa!...

Aqui o problema do sufrágio feminino interessa pouco, mormente agora que não há parlamento nem câmaras municipais, nem juntas, nem nada. Vivemos num regímen esquisito de ordem do dia. Nem se sabe o que foi ontem, o que é hoje, nem o que será amanhã. As mulheres andam preocupadas com a fome, com a alta da vida, com o corte em pensões... Enfim, numa trapalhada! Venha e traga muita coisa para me contar. Eu tenho passado um pouco mal do meu eterno reumatismo e agora uma grande crise de diabetes. Em todo o caso, trabalho.

Cumprimentos de todos desta casa.

Um abraço da sua muito amiga

Ana C. Osório

Não deixe de vir e de me escrever.

A Paulina Luisi do Uruguai ${ }^{34}$ está aí?

Conte muita coisa e diga algumas notícias interessantes para os jornais de cá. Sempre se vai deitando o barro à parede.

\section{CARTa 9}

Lisboa 10-11-192935

Minha querida amiga

Recebi a sua carta que muito estimei com o recorte do jornal que se refere à sua bela propaganda.

Deixou-nos aqui muita saudade na sua rápida vista de Estrela Cadente... Quando volta?

Dentro da revista que o José lhe mandou meti 2 jornais que saíam interessantes e hoje envio mais 2 com as boas respostas que dão duas senhoras de valor ao inquérito que está fazendo o Diário de Lisboa. Outras têm respondido fartamente. É melhor ignorálas. As que forem interessantes mandarei.

Aproveito a ida do portador, Sr. Alfredo Arenas de Lima Laner, para lhe enviar esta e apresentá-lo com

\footnotetext{
${ }^{34}$ Acrescento na linha inferior.

35 BR RJANRIO Q0.ADM.COR.A1929.20.p9-11
}

o maior interesse ao seu muito valimento aí. Como vê é um moço e com muita vontade de trabalhar. É primo da minha amiga Maria da Conceição Pereira de Eça, de quem the tenho falado e que dirige a página feminina do Século onde veio o seu retrato com um bom e grande artigo da Virgínia Quaresma. A M. ${ }^{a}$ Eça prometeu arranjar um exemplar para lhe mandar, visto não ter recebido o primeiro.

Ambas the pedimos que faça o que puder pelo nosso protegido, no sentido de o tornar aí um relacionado.

Quem sabe se aí irei muito breve?!... É bem possível.

Um grande abraço de sua muito amiga.

Ana C. Osório

\section{Referências}

BURKE, Peter. Uma história social do conhecimento [de Gutenberg a Diderot]. Rio de Janeiro: Jorge Zahar, 2003.

CASTRO, Zília Osório de. As intelectuais. In: CASTRO, Zília Osório de; ESTEVES, João; MONTEIRO, Natividade (Coord.). Mulheres na la República. Percursos, conquistas e derrotas. Lisboa: Colibri, 2011.

CASTRO, Zília Osório de; ESTEVES, João; MONTEIRO, Natividade (Coord.). Mulheres na la República. Percursos, conquistas e derrotas. Lisboa: Colibri, 2011.

CASTRO, Zila Osório de; ESTEVES, João. (Direcção). Dicionário no Feminino. Lisboa: Livros Horizonte, 2005.

COELHO, Nelly Novaes. Dicionário crítico de escritoras brasileiras. São Paulo: escrituras, 2002.

ESTEVES, João. Ana de Castro Osório (1872-1935). Lisboa: CIG, 2014.

.Feminismo, feminismos e sufragismo na 1 a República. In: CASTRO, Zília Osório de; ESTEVES, João; MONTEIRO, Natividade (Coord.). Mulheres na la a República. Percursos, conquistas e derrotas. Lisboa: Colibri, 2011.

GOMES, Angela Maria de Castro. A Grande Aliança de Ana de Castro Osório: um projeto político-pedagógico fracassado. Estudos do Século XX, v. 11, p. 20-43, 2011.

Em família: a correspondência entre Oliveira Lima e Gilberto Freire. In: (Org.). Escrita de si, escrita da História. Rio de Janeiro: Editora FGV, 2004.

A "grande aliança": um projeto político-pedagógico luso-brasileiro na Primeira República. Anais do XXVII Simpósio Nacional de História - ANPUH 2013. Natal, 2013. Disponível em: <http://www.snh2013.anpuh.org/resources/ anais/27/1362239883 ARQUIVO TextoAnaCOsorioanpuh13. pdf $>$. Acesso em: 15 jul. 2016.

Aventuras e desventuras de uma autora e editora portuguesa: Ana de Castro Osório e suas viagens ao Brasil. In: GOMES, Angela Maria de Castro; HANSEN, Patricia Santos (Org.). Intelectuais mediadores: práticas culturais e ação política. Rio de Janeiro: Civilização Brasileira, 2016.

LEITE, Miriam L. Moreira. Maria Lacerda de Moura: uma feminista utópica. Florianópolis: Mulheres, 2005. 
LOUSADA, Isabel. Entre Marias, Ana. De Castro Osório, Entre Correspondências. Anais do VII Seminário Internacional Mulher e Literatura. Caxias do Sul: UCS, 2015.

Pela Pátria: "A Cruzada das Mulheres Portuguesas" (1916-1938). In: XIX Colóquio de História Militar - 100 anos de regime republicano: políticas, rupturas e continuidades. Lisboa: Comissão Portuguesa de História Militar - Ministério da Defesa Nacional, 2011.

. Adelaide Cabete (1867-1935). Lisboa: Comissão para a cidadania e igualdade de gênero, 2010.

Perfil de uma pioneira: Adelaide Cabete (18671935). 2. ed., revista e aumentada. Lisboa: Associação Cedro, AMONET, CICS.NOVA, CELPUL, IECCPMA, MIMA, 2017.

LOUSADA, Isabel. LAGUARDIA, Angela. Maria Lacerda de Moura e Ana de Castro Osório: correspondência em trânsitos atlânticos e feministas. Navegações: revista de cultura e literaturas de língua portuguesa, v. 6, n. 1, jan./jun. 2013. Porto Alegre: PUCRS/CLEPUL (Universidade de Lisboa), 2013.

PEREIRA, Maria Apparecida Franco. Ana de Castro Osório e "a grande aliança": migrações intelectuais da aproximação de Portugal e Brasil, na Primeira República. Anais do XXVIII Simpósio Nacional de História. Florianópolis, SC: 2015. Disponível em: <http://www.snh2015.anpuh.org/ resources/anais/39/1435673181 ARQUIVO TextoMaria ApparecidaFrancoPereira.pdf $>$. Acessado em: 15 jul. 2016.
REMÉDIOS, Maria José. “Ana de Castro Osório e a construção da Grande Aliança entre os povos : dois manuais de escritora portuguesa adoptados no Brasil". Anais do I Congresso Brasileiro de História da Educação. Rio de Janeiro: Sociedade Brasileira de História da Educação, 2000. Disponível em: $<$ http://www.sbhe.org.br/novo/congressos/cbhe1/anais/109 maria jose.pdf $>$. Acesso em: 15 jul. 2000.

SCHUMAHER Schuma; BRAZIL, Érico Vital (Org.). Dicionário Mulheres do Brasil: de 1500 até a atualidade. 2. ed. Rio de Janeiro: Zahar, 2000.

SOIHET, Rachel. O feminismo tático de Bertha Lutz. Florianópolis: Ed. Mulheres; Santa Cruz do Sul: EDUNISC, 2006.

WOOLF, Virginia. Profissões para mulheres e outros textos feministas. Trad. Denise Bottmann. Porto Alegre: L\&PM, 2018.

Recebido: 03/10/2018

Aprovado: 09/11/2018

Autores:

EDUARDO DA CRUZ

Universidade do Estado do Rio de Janeiro (UERJ).

eduardodacruz@gmail.com

(D) 0000-0002-2150-9266

ANDREIA MONTEIRO DE CASTRO

Secretaria de Educação do Estado do Rio de Janeiro.

Polo de Pesquisas Luso-Brasileiras.

andreiaacastro@yahoo.com.br 